\title{
Malatya ili kayısılarında zararlı, Polydrusus ponticus Faust (Coleoptera: Curculionidae)'un zararı ve mekanik mücadelesi
}

\author{
Mechanical control and damage of Polydrusus ponticus Faust (Coleoptera: \\ Curculionidae) on apricot in Malatya province, Turkey
}

\author{
Naim ÖZTÜRK ${ }^{1}$ \\ M. Rifat ULUSOY ${ }^{2}$
}

\section{Summary}

This study was conducted in apricot orchards in Doğanşehir, Yeşilyurt, Battalgazi and Kale district of Malatya in 2010-2011. Polydrusus ponticus Faust (Coleoptera: Curculionidae) was identified in Turkey in previous years but there wasn't a detailed study on the pest since then. This study aimed to determine the damage type, damage rate and the effectiveness of mechanical control of the pest. Visual control method was used to define the damage type. In order to reveal the damage rate and a total of 1000 fruits on 10 trees in each orchard were rated as damaged or clean. Randomized block experimental design was used for mechanical control trail with 2 characters and 6 replications. The results were evaluated by monitoring 250 fruits per tree.

As a result, it is determined that $P$. ponticus adults causes crop losses by feeding on buds, leaves and shoots while larvae causes losses by feeding on apricot seed. It was monitored that only one larvae feeds in a single fruit. It was also monitored that the damaged fruit either dropped off before maturation or was hang off on the tree. It was determined that the average damage rate of $P$. ponticus was $5.8 \%$ in $2010,5.9 \%$ in 2011 and $5.9 \%$ as the average of the two years. The effectiveness of the mechanical control against $P$. ponticus was $95.5 \%$ in an orchard in Doğanşehir in 2010 while $95.7 \%$ in Battalgazi. The rates were $95.8 \%$ and $95.6 \%$ respectively in the second year of the trial. According to these results, average efficacy rate of siliconized fiber for the control of $P$. ponticus was found $95.6 \%$. Siliconized fiber application was determined as an alternative to chemical control.

Key words: Apricot, Polydrusus ponticus, damage, mechanical control

\section{Özet}

Bu çalışma; 2010-2011 yılllarında Malatya İline bağlı Doğanşehir, Yeşilyurt, Battalgazi ve Kale İlçesi kayısı bahçelerinde yürütülmüştür. Çalışmada, Türkiye'de var olduğu bilinen ancak bugüne kadar üzerinde çalışma yapılmayan, Polydrusus ponticus Faust (Coleoptera: Curculionidae)'un kayısılardaki zarar şekli, zarar oranı ve mekanik mücadele etkinliğinin belirlenmesi amaçlanmıştır. $P$. ponticus'un zarar şekli ile zarar oranının belirlenmesinde, gözle kontrol ve 1000 meyve (10 ağaç/bahçe) sayımı yöntemleri kullanılmıştır. Mekanik mücadele çalışması, tesadüf blokları deneme desenine göre iki karakter ve 6 tekrarlı olarak kurulmuş, değerlendirme 250 meyve/ağaç üzerinden yapılmıştır.

Çalışma sonucunda; $P$. ponticus erginlerinin kayısının tomurcuk, yaprak ve sürgünlerinde; larvasının ise meyve çekirdeğinde beslenerek ürün kaybına neden olduğu belirlenmiştir. Genellikle her meyvede bir larvanın bulunduğu ve zarar görmüş meyvelerin olgunlaşmadan yere döküldükleri veya ağaç üzerinde asılı kaldıkları gözlenmiştir. $P$. ponticus'un deneme yapılan kayısı bahçelerindeki ortalama meyve zarar oranının 2010 yılında \% 5.8 , 2011 yılında \% 5.9 olduğu ve her iki yıl ortalamasının ise \% 5.9 olduğu saptanmıştır. $P$. ponticus'a karşı uygulanan mekanik mücadele 2010 yılında Doğanşehir'deki bahçede \% 95.5 ve Battalgazi'de \% 95.7 oranında etkili bulunmuştur. İkinci yıl bu oranlar sırasıyla; \% 95.8 ve 95.6 olmuştur. Buna göre; Malatya İli kayısılarında zararlı, $P$. ponticus'un mücadelesinde slikonize elyaf uygulamasının 2010-2011 yılı ortalama etkinlik değeri \% 95.6 bulunurken, söz konusu uygulamanın kimyasal mücadeleye bir alternatif olabileceği saptanmıştır.

Anahtar sözcükler: Kayısı, Polydrusus ponticus, zarar, mekanik mücadele

\footnotetext{
${ }^{1}$ Biyolojik Mücadele Araştırma İstasyonu Müdürlüğü, 01321, Yüreğir, Adana

${ }^{2}$ Çukurova Üniversitesi Ziraat Fakültesi, Bitki Koruma Bölümü, 01330, Sarıçam, Adana

*Sorumlu yazar (Corresponding author) e-mail: ozturkn01@hotmail.com

Alınış (Received): 20.09.2013 Kabul ediliş (Accepted): 04.12.2013
} 


\section{Giriş}

Türkiye, 14.133.634 adet meyve veren ağaç sayısı ve yıllık 760.000 ton üretimiyle Dünya kayısı üretiminde ilk sırada yer almaktadır. Malatya ili yıllık 510.000 ton kayısı üretimiyle Türkiye kayısı üretiminin yaklaşık \% 67'lik kısmını gerçekleştirmektedir (Anonymous, 2013a). Malatya ilinde 2011 yılı verilerine göre, 120.000 ton kuru kayısı üretimi yapılmış olup, bu üretmin yaklaşık \% 90'ı ihraç edilerek Türkiye ekonomisine önemli katkı sağlanmıştır (Anonymous, 2013b).

Dünya'da kayısı tarımı yapılan alanlarda olduğu gibi, Türkiye kayısılarında da yetiştiricilik sorunlarının yanı sıra üretiminde doğrudan etkili olan ve bazı yıllarda önemli girdi artışına neden olabilen bir çok zararlı böcek türü bulunmaktadır (Viggiani, 1989; Cravedi \& Molinari, 1995; Anonymous, 1999; Hayat et al., 2001; Ulusoy et al., 2001; Öztürk et al., 2004). Bu türlerden birisi de, Polydrusus ponticus Faust (Coleoptera: Curculionidae)'dir. Söz konusu zararlı, bazı yıllar önemli popülasyonlar oluşturarak bazı bahçelerde ürün kayıplarına neden olmaktadır. Üründe meydana gelen bu kayıpları en aza indirebilmek için öncelikle sorun olan zararlının doğru tanılanması ve etkili bir mücadele yönteminin belirlenmesi gerekmektedir.

Polydrusus ponticus, Türkiye'nin farklı bölgelerinde yetiştiriciliği yapılan birçok meyve çeşidinde daha önce tespit edilmiş bir tür olmasına rağmen (Lodos, 1960; İren \& Ahmed, 1973; Kılıç \& Aykaç, 1989; Ayaz \& Yücel, 2010), bugüne kadar zararlı hakkında faunistik ve gözlem sonuçları dışında herhangi bir çalışma yürütülmemiştir. $P$. ponticus konukçusu olduğu bitkinin birçok organında beslenmesinin yanı sıra, Malatya ilinde kayısı meyvelerinde beslenmesi sonucu yapmış olduğu zararı öne çıkmaktadır. Zararı, kayısının çekirdeğinde beslenerek meyvenin zamanından önce olgunlaşıp dökülmesine, çürümesine ve dolayısıyla ürün kaybına neden olmaktadır. Bu durum ise, üretici ve ihracatçı tarafından kesinlikle arzu edilmemektedir.

Bu çalışmada; Türkiye'de daha önce varlığı bilinen ancak bugüne kadar üzerinde herhangi bir çalışma yapılmayan, $P$. ponticus'nin Malatya ili kayısılarındaki zarar şekli, zarar oranı ve mekanik mücadelenin etkinliğiyle ilgili sonuçlara yer verilmiştir. Elde edilen verilerin, kayısı bahçelerinde yürütülecek entegre mücadele çalışmaları ile benzer zararlı türlerle ilgili yapılacak çalışmalara kaynaklık edeceği kanısındayız.

\section{Materyal ve Yöntem}

Çalışmanın ana materyalini; Polydrusus ponticus Faust (Coleoptera: Curculionidae), P. ponticus ile bulaşık kayısı bahçeleri ve silikonize elyaf oluşturmuştur.

\section{Polydrusus ponticus'un kayısı meyvesindeki zarar şekli}

Çalışma; Malatya iline bağı Doğanşehir, Yeşilyurt, Battalgazi ve Kale ilçesi kayısı bahçelerinde $P$. ponticus'un meyvede beslenme sonucu oluşturduğu zarar şeklini belirlemek amacıyla yürütülmüştür. Bunun için; $P$. ponticus ile önceden bulaşık olduğu bilinen kayısı bahçelerine vejatasyon dönemi içerisinde (nisan-ağustos) periyodik olmayan arazi çıkışları düzenlenmiştir. Bu çıkışlar, zararın belirgin olarak görüldüğü hasada yakın (haziranın ilk yarısı ile temmuz ayı) dönemde haftalık olarak yapılmıştır. Örnekleme yapılan bahçelerde bahçeyi temsil edecek şekilde rasgele belirlenmiş verim durumu iyi olan ağaçların farklı yön ve yüksekliklerindeki meyvelerde gözle kontroller yapılmış ve $P$. ponticus'un meyvedeki zararı saptandığında; zarar belirtisi, beslenme yeri ve şekli, bitkinin fenolojik dönemi ayrı ayrı kaydedilmiştir. Örneklemelerin, mümkün olabildiğince adı geçen ilçelerdeki farklı yer ve bahçelere gidilerek yapılmasına özen gösterilmiştir. 


\section{Polydrusus ponticus'un kayısıdaki zarar oranının belirlenmesi}

Çalışma; Malatya ilinde yoğun olarak kayısı yetiştiriciliğinin yapıldığı Doğanşehir, Yeşilyurt, Battalgazi ve Kale ilçesinde o yöreyi temsil edecek şekilde ve her ilçeden üç farklı bahçede yürütülmüştür. Bahçeler; $8 \times 8$ ve 10×10 m mesafelerde dikilmiş, damla sulama sistemi ile sulanmakta olup, ağırıklı olarak Hacıhaliloğlu çeşidi ile tesis edilmiştir (Çizelge 1). P. ponticus'un zarar oranını belirlemek için her yıl hasattan yaklaşık bir ay önce (haziranın ilk yarısı) her bahçenin 5 farklı noktasından (4 kenar +1 orta kısım) ve her noktadan da meyve verimi iyi durumda olan ikişer ağaç olmak üzere toplam 10 ağaç sayım ağacı olarak işaretlenmiştir. Sayımlar, her yılın hasat döneminde yılda bir kez yapılmıştır. Bunun için sayım ağaçlarının altına silkme yöntemiyle dökülen (Şekil 1a) meyvelerden rasgele seçilmiş 1000 meyve/ağaç gözle kontrol edilmiş ve sonuçlar ayrı ayrı kayıt edilmiştir. Sayımlar sırasında, meyve üzerinde $P$. ponticus'un zarar belirtisi saptandığında (Şekil $1 \mathrm{~b}$ ), o meyve bulaşık olarak kabul edilmiştir. Ayrıca, hasat öncesi sayım ağaçlarının altına $P$. ponticus'un zararı nedeniyle dökülen meyveler de toplanmış ve ağaç başına sayılan 1000 adet meyveye ilave edilerek değerlendirilmiştir.
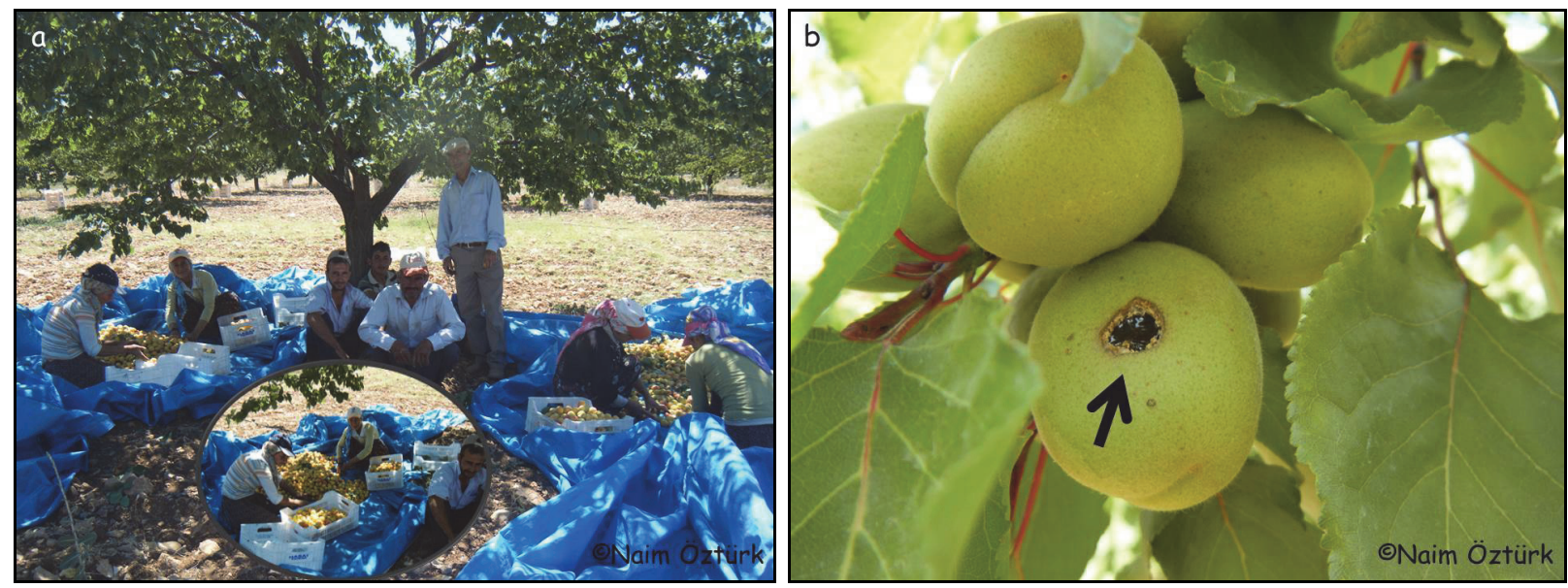

Şekil 1. Malatya ilinde silkme yöntemiyle kayısı hasadı (a) ve Polydrusus ponticus Faust'un kayısı meyvesindeki zararı (b).

Malatya ilinde $P$. ponticus'un meyvedeki zarar oranını belirlemeye yönelik çalışmaların yürütüldüğü kayısı bahçelerine ait bilgiler Çizelge 1'de verilmiştir.

Çizelge 1. Malatya ilinde Polydrusus ponticus'un zarar oranının belirlendiği kayısı bahçelerine ait bilgiler

\begin{tabular}{lllcc}
\hline İlçe & Köy/Belde & Çeşit & Yaş & Alan (da) \\
\hline Doğanşehir & Yuvalı & Hacıhaliloğlu, Şekerpare & 14 & 50 \\
& Çığlık & Hacıhaliloğlu & 17 & 37 \\
& Sürgü & $\begin{array}{l}\text { Hacıhaliloğlu, Hasanbey, } \\
\text { Şekerpare }\end{array}$ & 12 & 43 \\
& Cumhuriyetörnek & Hacıhaliloğlu, Kabaaşı & 15 & 55 \\
\hline Yeşilyurt & Gözene & Hacıhaliloğlu, Şekerpare & 15 & 63 \\
& Görgü & Hacıhaliloğlu & 18 & 38 \\
\hline Battalgazi & Boran & Hacıhaliloğlu, Tokaloğlu, & 20 & 70 \\
& Şekerpare & 15 & 58 \\
& Hasırcılar & Hacıhaliloğlu & 16 & 44 \\
\hline Kale & Dilek & Hacıhaliloğlu & 19 & 52 \\
& Kıyıcak & Hacıhaliloğlu, Tokaloğlu & 17 & 35 \\
& Akuşağı & Hacıhaliloğlu & 13 & 50 \\
\hline
\end{tabular}




\section{Polydrusus ponticus'un mekanik mücadelesi}

Çalışma; Polydrosus ponticus'un kayısı meyvelerindeki zarar şekli ve zarar oranının belirlendiği Doğanşehir ve Battalgazi ilçelerindeki $P$. ponticus zararının yoğun olduğu birer bahçede olmak üzere toplam 2 bahçede yürütülmüştür. Çalışmada; silikonize elyaf her yıl sürgün gözleri uyanmaya başladığında (mart ayının ikinci yarısı-nisan ayı başı) deneme ağaçlarının gövdesine yerden $70-80 \mathrm{~cm}$ yükseklik ve yaklaşık $30 \mathrm{~cm}$ genişliğinde çepeçevre sarılarak, ortasından rafya ile bağlanmıştır (Altındişli et al., 2009). Ayrıca, yere değen dallar kesilmiş ve aşırı meyve yüklü dallara destek olarak kullanılan hereklere de elyaf bağlanmıştır. Deneme süresince haftalık olarak elyaflarda yakalanan erginler toplanarak öldürülmüş ve rüzgar vb. nedenlerle bozulan elyaflar düzeltilerek yeniden bağlanmıştır. Denemenin etkilenmemesi amacıyla, deneme öncesi ağaçların dip kısımlarında bulunan yabancıotlar ile gövdedeki kavlamış kabuklar temizlenmiştir.

Deneme; tesadüf blokları deneme desenine göre iki karakterli [mekanik mücadele (MM)+ilaçsız kontrol (IK)] ve 6 tekrarlı olarak kurulmuştur. Her blok 9 ağaçtan oluşmuş olup, bloklar arasında ikişer sıra emniyet şeridi bırakılmış, her bloktaki tüm ağaçlar sayım ağacı olarak değerlendirilmiş (Altındişli et al., 2009) ve her ağaçtan da 250 adet meyve sayımı yapılmıştır. Denemede, P. ponticus'un mekanik mücadelesi amacıyla kullanılan silikonize elyaf, ilaçsız kontrol uygulaması ile karşılaştııılmıştır (Anonymous, 2012). Değerlendirme, zarar görmüş kayısı meyve sayısı üzerinden \% Abbott formülüne göre yapılmıştır.

\section{Araştırma Sonuçları ve Tartışma}

\section{Polydrusus ponticus'un kayısı meyvesindeki zarar şekli}

Çalışmanın yürütüldüğü her iki yılın vejatasyon döneminde ve özellikle zararın belirgin olarak görüldüğü haziran ayının ilk yarısından sonraki arazi çalışmalarında, $P$. ponticus'un zararıyla ilgili gerekli kontroller yapılmış ve elde edilen bulgular kayıt edilmiştir. Yapılan gözlem ve kontrollerde; $P$. ponticus erginlerinin (Şekil 2a) kayısının tomurcuk, yaprak ve sürgünlerinde; larvanın ise meyvede beslendiği belirlenmiştir. Ancak, P. ponticus'un en önemli zararını meyvede yaparak (Şekil 2b), bazı yıllarda kayısıda önemli ürün kayıplarına neden olduğu görülmüştür.
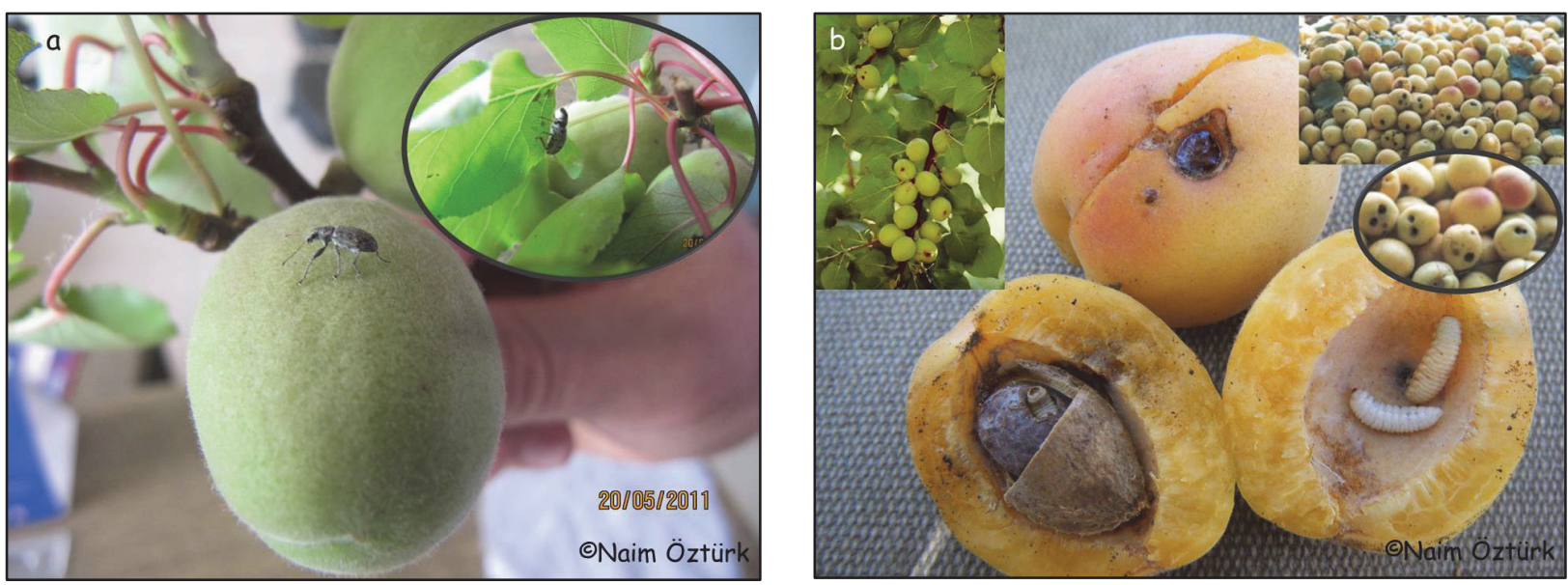

Şekil 2. Polydrusus ponticus'un ergini (a), kayısı meyvesindeki beslenme zararı ve larvası (b). 
Lodos (1960), Malatya ili kayısılarıda yaptığı bir çalışmada; Curculionidae familyasına ait Rhynchites smyrnensis Desbr., P. ponticus, Otiorhynchus meridionalis Gyll., O. lodosi Osella , O. turca Boheman türlerinin kayısının kök, yaprak, filiz, tomurcuk, çiçek ve meyvelerinde beslendiklerini bildirmiştir. Benzer şekilde Ankara, Kayseri, Kütahya, Bolu, Mersin (Mut) ve Sivas illerinde yürütülen bir çalışmada da; Polydrosus ponticus'un elma, kayısı, kiraz, armut, şeftali, erik ve ayva bahçelerinde saptandığı bildirilmiştir (İren \& Ahmed, 1973).

Polydrusus ponticus erginlerinin uçma yeteneği olmadığı için kayısı ağacına genellikle gövde kısmından, nadirende dalların altına destek amaçlı olarak yerleştirilen herekler ile yere değen dallardan tırmanarak çıktıkları belirlenirken, zararlının daha çok alt dallardaki meyveleri tercih ettiği gözlenmiştir. Genellikle bir meyvede bir larva bulunduğu, ancak nadirende olsa bazı meyvelerde iki adet larvanın da beslendiği görülmüştür (Şekil 2b). P. ponticus'un çağla döneminde meyve içerisine yumurtasını bıraktığı, yumurtadan çıkan larvanın meyve çekirdeğinde beslendiği ve olgunlaşan larvanın meyvenin etli kısmında bir delik açarak toprakta pupa olmak üzere dışarı çıktığı belirlenmiştir (Şekil 2b). Bu şekilde zarar görmüş meyvelerin ya olgunlaşmadan yere düştükleri yada ağaç üzerinde asılı olarak kaldıkları gözlenmiştir. Lodos (1960), Curculionidae (R. smyrnensis, P. ponticus, O. meridionalis, O. lodosi, O. turca) türlerinin yumurtasını mayıs ayı içerisinde kayısı meyvelerinde açmış oldukları 2-3 mm'lik bir deliğe koyarak hortumu ile içeri doğru ittiklerini ve daha sonra çıkarmış oldukları meyve talaşı ile de kapattıklarını bildirmiştir. Araştırıcı, yumurtadan çıkan larvanın meyvede beslendiğini ve daha sonra da meyveyi terk ederek toprakta pupa olduğunu belirtmiştir. Hayat et al. (2001), Curculionidae familyasına ait Rhynchites bacchus L., Polydrusus inustus Germar, Anthonomus pomorum L., Curculio glandium Marsham, Lixus subtilis Boheman ve Otiorhynchus anatolicus Boheman türlerinin Erzurum ve çevre illeri kayısılarının tomurcuk, yaprak ve meyvelerinde zarar yaptıklarını, sap kısmında beslenmeleri sonucu meyve dökümü, etli kısımda beslenmeleri sonucu ise ürünün pazar değerinin düştüğünü belirtmişlerdir.

\section{Polydrusus ponticus'un kayısıdaki zarar oranının belirlenmesi}

Malatya ili kayısılarında zararlı, $P$. ponticus'un zarar oranını belirlemek için yürütülen bu çalışma; yörede ekonomik olarak kayısı yetiştiriciliği yapılan ilçelerde ve önceki yıllarda $P$. ponticus zararının görüldüğü bahçelerde yürütülmüştür (Çizelge 1). Çalışmanın yapıldığı kayısı bahçelerine ait $P$. ponticus meyve bulaşıkılık oranları Çizelge 2'de verilmiştir.

Çizelge 2. Malatya ili kayısı bahçelerinde zararlı Polydrusus ponticus'un 2010-2011 yılı meyve zarar oranları

\begin{tabular}{|c|c|c|c|c|c|c|c|c|c|c|c|c|c|}
\hline & \multirow{2}{*}{$\begin{array}{l}\text { İlçe Adı } \\
\text { Bahçe no }\end{array}$} & \multicolumn{3}{|c|}{ Doğanşehir } & \multicolumn{3}{|c|}{ Yeşilyurt } & \multicolumn{3}{|c|}{ Battalgazi } & \multicolumn{3}{|c|}{ Kale } \\
\hline \multirow{6}{*}{ 웅 } & & 1 & II & III & I & II & III & I & II & III & I & II & III \\
\hline & Bulaşık meyve & 60 & 90 & 80 & 40 & 70 & 50 & 60 & 50 & 90 & 50 & 40 & 30 \\
\hline & Temiz meyve & 940 & 910 & 920 & 960 & 930 & 950 & 940 & 950 & 910 & 950 & 960 & 970 \\
\hline & \% Bulaşıklık & 6 & 9 & 8 & 4 & 7 & 5 & 6 & 5 & 9 & 5 & 4 & 3 \\
\hline & Ort. bulaşıklık & & $\% 7.6$ & & & $\% 5.3$ & & & $\% 6.6$ & & & $\% 4.0$ & \\
\hline & Genel ort. bulaşıklık & \multicolumn{12}{|c|}{5.8} \\
\hline \multirow{6}{*}{ 듕 } & Bulaşık meyve & 40 & 80 & 70 & 50 & 50 & 60 & 70 & 60 & 90 & 50 & 60 & 40 \\
\hline & Temiz meyve & 960 & 920 & 930 & 950 & 950 & 940 & 930 & 940 & 910 & 950 & 940 & 960 \\
\hline & $\%$ Bulaşıklılık & 4 & 8 & 7 & 5 & 5 & 6 & 7 & 6 & 9 & 5 & 6 & 4 \\
\hline & Ort. bulaşıklık & & $\% 6.3$ & & & $\% 5.3$ & & & $\% 7.3$ & & & $\% 5.0$ & \\
\hline & Genel ort. bulaşıklık & \multicolumn{12}{|c|}{5.9} \\
\hline & İki yıl ort. bulaşıklık & \multicolumn{3}{|c|}{$\% 6.9$} & \multicolumn{3}{|c|}{$\% 5.3$} & \multicolumn{3}{|c|}{$\% 6.9$} & \multicolumn{3}{|c|}{$\% 4.5$} \\
\hline
\end{tabular}


Çizelge 2 incelendiğinde; Doğanşehir, Yeşilyurt, Battalgazi ve Kale ilçelerindeki 12 farklı kayısı bahçesinde yapılan kontrol ve sayımlarda; 2010 yılında $P$. ponticus'un ortalama zarar \% 5.8 bulunurken, 2011 yılında bu oranın \% 5.9 olduğu belirlenmiştir. Çalışmada, birinci yıl en fazla ortalama bulaşık meyve \% 7.6 ile Doğanşehir ve \% 6.6 ile Battalgazi'deki bahçelerde bulunmuştur. İkinci yıl ise, en fazla bulaşıklııı 2010 yılının aksine \% 7.3 ile Battalgazi, \% 6.3 ile Doğanşehir ilçesinde saptanmıştır. Çalışmanın yürütüldüğü 2010-2011 yıllarında 4 ilçedeki 12 bahçenin bulaşıklık oranları birlikte değerlendirildiğinde; bu oran \% 3-9 arasında değişirken, her iki yılın ortalama bulaşıklılık değerinin ise \% 5.9 (\% 4.5-6.9) olduğu belirlenmiştir (Çizelge 2). Ancak, bu durumun Malatya ili kayısı bahçelerinin tamamında aynı olmadığı bilinmeli ve bazı bahçelerde bulaşıklıığın sıfır olduğu gözardı edilmemelidir. Buna göre; Malatya ili kayısı bahçelerinde zararlı $P$. ponticus'un sorun olduğu bahçelerin daha çok ormana yakın olanlarda görüldüğü ve bir genelleme yapılacak olursa, bölgede zarar oranının \% 0-9 arasında değiştiği söylenebilir.

\section{Polydrusus ponticus'un mekanik mücadelesi}

Çalışma, P. ponticus'un sorun olduğu Doğanşehir (çığlık) ve Battalgazi (Hasırcılar) ilçelerindeki birer bahçede yürütülmüştür (Çizelge 1). Çalışmanın yürütüldüğü 2010-2011 yıllarında ve birinci yıl 05 Nisan ve ikinci yı 28 Mart tarihlerinde silikonize elyaflar ağaçların gövdelerine metotta belirtildiği şekilde bağlanmıştır (Şekil 3a).
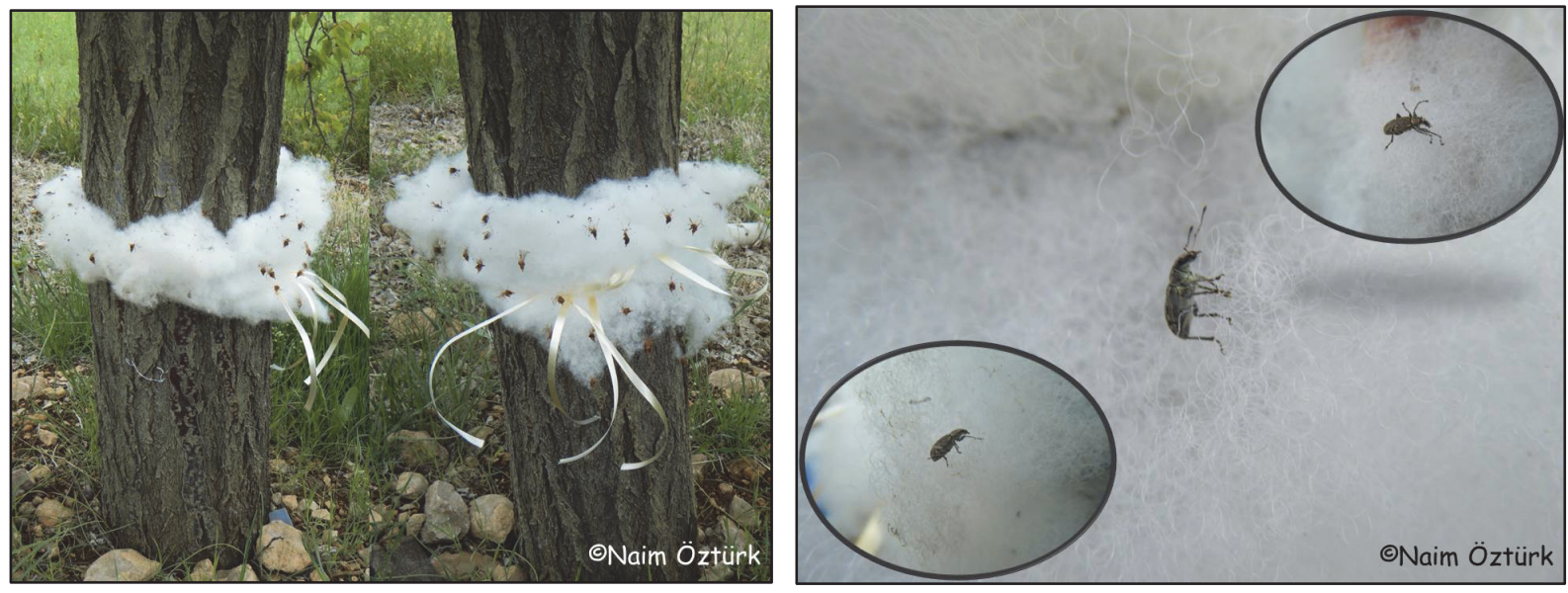

Şekil 3. Polydrusus ponticus'a karşı elyaf uygulaması (a) ve erginlerin elyaf ile yakalanışı (b).

Çalışmada; 2010-2011 yıllarında her yıl hasat sırasında deneme parselindeki ağaçlarda yapılan 250 'şer adet meyvenin sayım sonuçları çizelge 3'te verilmiştir. Buna göre, her bloktan 2250 adet ve denemenin tamamından ise her yıl için toplam; 13500 meyve sayımı yapılarak çalışmanın etkinliği değerlendirilmiştir. Çalışmanın birinci yılında yapılan denemede ilaçsız kontrol parsellerindeki zarar oranı ortalama Doğanşehir'de \% 8.06 (6.88-9.11) ve Battalgazi'deki bahçede \% 8.73 (7.86-9.33) olmuştur. Mekanik mücadele uygulanan parsellerdeki ortalama zarar oranları ise yine Doğanşehir'deki bahçede \% $0.35(0.22-0.48)$ olurken, Battalgazi'de \% $0.36(0.26-0.44)$ olarak bulunmuştur. $P$. ponticus'a karşı uygulanan mekanik mücadelenin etkisi her iki ilçede de birbirine yakın sonuçlar elde edilmiş olup, Doğanşehir'de \% 95.5 ve Battalgazi'de \% 95.7 olarak hesaplanmıştır. İkinci yıl ise, kontrol parsellerindeki zarar oranı ortalama Doğanşehir'de \% 8.39 (7.15-9.20) ve Battalgazi'deki bahçede de \% 8.44 (7.33-9.37) olmuştur. Mekanik mücadeledeki ortalama zarar oranları, Doğanşehir'deki bahçede \% 0.34 (0.26-0.44) ve Battalgazi'de \% 0.35 (0.26-0.48) olarak bulunmuştur. Uygulanan mekanik mücadelenin $P$. ponticus'a 
karşı etkisi yine birbirine yakın olup, Doğanşehir'de \% 95.8 ve Battalgazi'de ise \% 95.6 olarak hesaplanmıştır. Mekanik mücadele uygulamasının her iki yıl ortalama değerinin ise, \% 95.6 olduğu belirlenmiştir. Benzer şekilde Ege Bölgesi bağlarında zararlı Maymuncuklar (Otiorhynchus spp. ve Megamecus spp.)'ın mekanik mücadelesi üzerine 2000-2002 yıllarında yapılan bir çalışmada; slikonize elyaf uygulamasının birinci yıl \% 100, \% 100, \% 95.85; ikinci yıl \% 82.75, \% 91.70, \% 93.45 ve üçüncü yıl ise \% 97.76, \% 95.53 ve \% 93.21 oranında etki gösterdiğini bildirmişlerdir. Araştırıcılar, Bağ maymuncuklarına karşı slikonize elyaf uygulamasının ortalama \% 90'nın üzerinde etkili olduğunu ve kimyasal mücadeleye alternatif olabileceğini vurgulamışlardır (Altındişli et al., 2009).

Çizelge 3. Malatya ili kayısılarında, Polydrosus ponticus'a karşı 2010-2011 yılında uygulanan mekanik mücadelenin etkinliği

\begin{tabular}{|c|c|c|c|c|c|c|c|c|c|c|}
\hline \multirow[t]{2}{*}{$\begin{array}{l}\text { Deneme } \\
\text { yeri }\end{array}$} & \multirow[t]{2}{*}{ Karekter } & \multirow[t]{2}{*}{ Tekerrür } & \multicolumn{2}{|c|}{ Sağlam meyve } & \multicolumn{2}{|c|}{ Kurtlu meyve } & \multicolumn{2}{|c|}{$\begin{array}{c}\text { Kurtlu meyve } \\
\text { oranı (\%) }\end{array}$} & \multicolumn{2}{|c|}{$\%$ Etki } \\
\hline & & & 2010 & 2011 & 2010 & 2011 & 2010 & 2011 & 2010 & 2011 \\
\hline \multirow{14}{*}{ 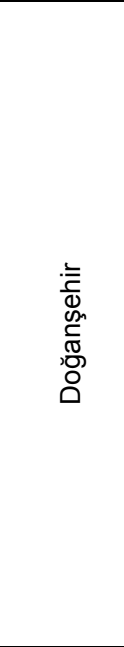 } & \multirow{6}{*}{ 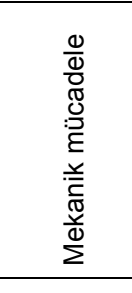 } & 1 & 2243 & 2241 & 7 & 9 & 0.31 & 0.40 & 96.5 & 95.6 \\
\hline & & ॥ & 2245 & 2243 & 5 & 7 & 0.22 & 0.31 & 96.8 & 96.3 \\
\hline & & III & 2239 & 2244 & 11 & 6 & 0.48 & 0.26 & 94.2 & 97.0 \\
\hline & & IV & 2242 & 2242 & 8 & 8 & 0.35 & 0.35 & 96.1 & 95.4 \\
\hline & & V & 2242 & 2240 & 8 & 10 & 0.35 & 0.44 & 95.2 & 95.0 \\
\hline & & VI & 2240 & 2243 & 10 & 7 & 0.44 & 0.31 & 94.2 & 95.6 \\
\hline & & \multicolumn{5}{|c|}{ Ortalama } & 0.35 & 0.34 & 95.5 & 95.8 \\
\hline & \multirow{6}{*}{ 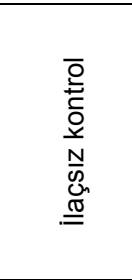 } & I & 2045 & 2043 & 205 & 207 & 9.11 & 9.20 & & \\
\hline & & II & 2095 & 2058 & 155 & 192 & 6.88 & 8.53 & & \\
\hline & & III & 2063 & 2049 & 187 & 201 & 8.31 & 8.93 & & \\
\hline & & IV & 2045 & 2075 & 205 & 175 & 9.11 & 7.77 & & \\
\hline & & V & 2085 & 2052 & 165 & 198 & 7.33 & 8.80 & & \\
\hline & & VI & 2078 & 2089 & 172 & 161 & 7.64 & 7.15 & & \\
\hline & & & & talama & & & 8.06 & 8.39 & & \\
\hline \multirow{14}{*}{ 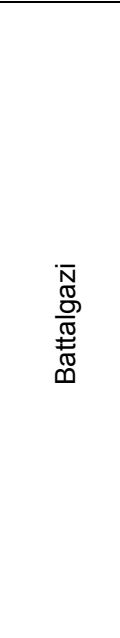 } & \multirow{6}{*}{ 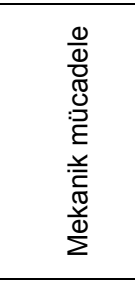 } & 1 & 2240 & 2243 & 10 & 7 & 0.44 & 0.31 & 95.2 & 96.5 \\
\hline & & II & 2242 & 2239 & 8 & 11 & 0.35 & 0.48 & 95.8 & 93.6 \\
\hline & & III & 2240 & 2244 & 10 & 6 & 0.44 & 0.26 & 94.4 & 97.0 \\
\hline & & IV & 2243 & 2241 & 7 & 9 & 0.31 & 0.40 & 96.5 & 95.7 \\
\hline & & V & 2241 & 2242 & 9 & 8 & 0.40 & 0.35 & 95.3 & 95.8 \\
\hline & & VI & 2244 & 2242 & 6 & 8 & 0.26 & 0.35 & 97.2 & 95.2 \\
\hline & & \multicolumn{5}{|c|}{ Ortalama } & 0.36 & 0.35 & 95.7 & 95.6 \\
\hline & \multirow{6}{*}{ 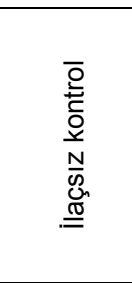 } & 1 & 2043 & 2047 & 207 & 203 & 9.20 & 9.02 & & \\
\hline & & II & 2058 & 2079 & 192 & 171 & 8.53 & 7.60 & & \\
\hline & & III & 2073 & 2052 & 177 & 198 & 7.86 & 8.80 & & \\
\hline & & IV & 2049 & 2039 & 201 & 211 & 8.93 & 9.37 & & \\
\hline & & $\mathrm{V}$ & 2058 & 2058 & 192 & 192 & 8.53 & 8.53 & & \\
\hline & & VI & 2040 & 2085 & 210 & 165 & 9.33 & 7.33 & & \\
\hline & \multicolumn{6}{|c|}{ Ortalama } & 8.73 & 8.44 & & \\
\hline
\end{tabular}

Sonuç olarak; Malatya ili (Doğanşehir, Yeşilyurt, Battalgazi ve Kale ilçesi) kayısı bahçelerinde zararlı $P$. ponticus erginlerinin kayısının tomurcuk, yaprak ve sürgünlerinde; larvasının ise meyve çekirdeğinde beslenerek bazı yıllarda, özellikle ormanlık alanlara yakın bahçelerde önemli ürün kayıplarına neden olduğu belirlenmiştir. Uçma özelliği olmayan zararlının kayısı ağacına genellikle gövdeden, nadirende aşırı yüklü dallara destek olarak kullanılan herekler ile yere değen dallardan 
tırmanarak çıktığı ve daha çok alt dallardaki meyveleri tercih ettiği gözlenmiştir. $P$. ponticus'un çağla dönemindeki meyveye yumurtasını bıraktığı, larvanın meyve çekirdeğinde beslendiği, genellikle her meyvede bir larvanın bulunduğu ve olgunlaşan larvanın meyve etinde delik açarak toprakta pupa olmak üzere dışarı çıktığı saptanmıştır. Bu şekilde zarar görmüş meyvelerin ise, ya olgunlaşmadan yere düştükleri yada ağaç üzerinde asılı kaldıkları görülmüştür. $P$. ponticus'un deneme yapılan kayısı bahçelerindeki ortalama meyve zarar oranı birinci yıl $\% 5.8$, ikinci yıl \% 5.9 olmuş, iki yılın ortalama değeri ise \% 5.9 bulunmuştur. Birinci yıl en fazla ortalama bulaşık meyve \% 7.6 ile Doğanşehir ve \% 6.6 ile Battalgazi'de, 2011 yılında ise \% 7.3 Battalgazi ve \% 6.3 ile Doğanşehir'deki bahçede saptanmıştır. Her iki yıl verilerine göre, deneme yapılan tüm bahçelerdeki bulaşıklık oranı \% 3-9 arasında değişirken, ortalama bulaşıklık değerinin \% 5.9 olduğu belirlenmiştir. Ancak, bu durumun Malatya ili kayısı bahçelerinin tamamında aynı olmadığı ve bulaşıklığın bazı bahçelerde $\% 0$ olduğu, dolayısıyla da zararın il genelinde \% 0-9 arasında değiştiği söylenebilir. Çalışmada ayrıca, P. ponticus'un mekanik mücadelesinde kullanılan silikonize elyaf uygulmasının etkinliği, birinci yıl Doğanşehir'de \% 95.5 ve Battalgazi'de \% 95.7 olurken, aynı değer ikinci yıl sırasıyla \% 95.8 ve \% 95.6 olarak hesaplanmıştır. Mekanik mücadele uygulamasının iki yıl ortalama değerinin ise, \% 95.6 olduğu belirlenmiştir. Buna göre; Malatya ili kayısılarında $P$. ponticus zararından kaynaklanabilecek ürün kayıplarının en aza indirilmesi ve zararlının mücadelesinde başarılı olabilmek için; öncelikle zararıının iyi tanınması, kayısıdaki zarar şekli ve zarar oranının iyi bilinmesi gerekmektedir. Ayrıca, $P$. ponticus'a karşı her yıl düzenli kontroller yapılarak, uygun ve etkili bir mücadele yöntemi uygulanmalı, mevcut yöntemlerden ise kültürel önlemler, mekanik, biyoteknik ve biyolojik mücadeleye öncelik verilerek, kimyasal mücadele en son olarak düşünülmelidir.

\section{Teşekkür}

Çalışmada, Polydrusus ponticus Faust (Coleoptera: Curculionidae)'un teşhisini yapan Sn. Yrd. Doç. Dr. Sakin Vural VARLI (Balıkesir Üniversitesi Fen Edebiyat Fakültesi, Biyoloji Bölümü)'ya teşekkür ederiz.

\section{Yararlanılan Kaynaklar}

Altındişli, F.Ö., F. Özsemerci, T. Koçlu, A. Altındişli \& B. Isşçi, 2009. "Bağlarda zararlı maymuncuklar (Otiorhynchus spp. ve Megamecus spp., Col.: Curculionidae)'a karşı kimyasal mücadeleye alternatif mekanik mücadele, 298300. Türkiye 7. Bağcılık ve Teknoloji Sempozyumu, Manisa.

Anonymous, 1999. Integrated Pest Management for Stone Fruits (Apricot, Insects and Mites). UC IPM Program Pest Management Guidelines: Statewide IPM Program, Agriculture and Natural Resources, Universty of California, 264 pp. (Web sayfası: http://www.ipm.ucdavis.edu) (Erişim tarihi: Mayıs 2013).

Anonymous, 2008. Zirai Mücadele Teknik Talimatları (Meyve ve Bağ Zararılıarı). T.C. Tarım ve Köyişleri Bakanlığı, Tarımsal Araşt. Genel Müdürlüğü, Bitki Sağlığı Araştırmaları Daire Başkanlığı, Ankara, Cilt: 4, 388 s. . (Web sayfası: http://www.tagem.gov.tr) (Erişim tarihi: Haziran 2013).

Anonymous, 2012. Zirai Mücadele Standart İlaç Deneme Metotları (Meyve-Bağ Zararlıları). T.C. Gıda, Tarım ve Hayvancılık Bakanlığı, Tarımsal Araşt. ve Politikalar Genel Müdürlüğü, Bitki Sağlığı Araştırmaları Daire Bşk., Ankara. (Web sayfası: www.tarim.gov.tr) (Erişim tarihi: Mayıs 2013).

Anonymous, 2013a. 2012 Yılı Bitkisel Üretim İstatistikleri, Türkiye İstatistik Kurmu (TUiK), Ankara. (Web sayfası: http://www.tuik.gov.tr) (Erişim tarihi: Haziran 2013).

Anonymous, 2013b. T.C. Ekonomi Bakanlığı, İhracat Genel Müdürlüğü, Tarım Ürünleri Daire Başkanlığı 2011 Yılı Verileri. (Web sayfası: http://www.ibp.gov.tr) (Erişim tarihi: Temmuz 2013).

Ayaz, T. \& A. Yücel, 2010. Elazığ ili elma alanlarında bulunan zararlı ve yararlı arthropod türlerinin belirlenmesi üzerine araştırmalar. HR.Ü.Z.F.Dergisi, 14 (1): 9-16. 
Cravedi, P. \& F. Molinari, 1995. Apricot pests in Italy. Integrated Plant Protection in Stone Fruit. IOBC wprs Bull.. Bull. OILB srop, 18 (2): 43-46.

Hayat, R., Ş. Güçlü \& H. Özbek, 2001. "Erzurum ve çevre illerde kayısılarda bulunan fitofag ve avcı arthropod türleri, 249-256”. I. Sert Çekirdekli Meyveler Sempozyumu (25-28 Eylül 2001), Atatürk Bahçe Kült. Merkez Araş. Enst., Yalova.,

İren, Z. \& , M. K. Ahmed1973. The microlepidoptera and deciduous fruit pests of Turkey. Bitki Koruma Bülteni (II. Kısım), Ek Yayın (1): 35-83.

Kılıç, M. \& M.K. Aykaç, 1989. Karadeniz Bölgesi şeftali bahçelerindeki zararlılarla mücadelenin yönetimi üzerinde araştırmalar. Bitki Koruma Bülteni, 29 (3-4): 211-241.

Lodos, N., 1960. Orta Anadolu'da Meyve Ağaçlarında Zarar yapan Curculionidae "Hortumlu Böcekler" Türleri Üzerinde Sistematik Araştırmalar. Ege Üniversitesi Ziraat Fakültesi Yayınları, No: 29, s.: 66.

Öztürk, N., M.R. Ulusoy, L. Erkılıç \& S. (ÖImez) Bayhan, 2004. Malatya ili kayısı bahçelerinde saptanan zararlılar ile avcı türler. Bitki Koruma Bülteni, 44 (1-4): 1-13.

Ulusoy, M.R., L. Erkılıç, N. Öztürk, S. Ölmez \& N. Uygun, 2001. “Kayısı zararlıları ve mücadelesi, 61-68”. Kayısı Sempozyumu Bildirileri (5 Nisan 2001), Kayısı Araştırma, Geliştirme ve Tanıtma Vakfı, Malatya..

Viggiani, G., 1989. "Pest of apricots, 481-486". IX International Symp. on Apricot Culture (09-15 July 1989), Caserta,. Department of Agricultural Entomology and Zoology. University of Naples, Portici/ltaly 
